\title{
Unveiling the behaviour of policy reaction function in Thailand: A pre and post crisis investigation
}

\author{
Lavaneesvari Manogaran*, Siok Kun Sek \\ School of Mathematical Sciences, Universiti Sains Malaysia, 11800 Minden, Penang, Malaysia
}

\section{A RT ICLE INFO}

\section{Article history:}

Received 21 February 2017

Received in revised form

18 September 2017

Accepted 9 October 2017

\section{Keywords:}

Inflation targeting

Monetary policy

Threshold estimation

\begin{abstract}
A B S T R A C T
Thailand was one of the first emerging Asian economies to collapse following the financial crisis of 1997-1998. Correspondingly the monetary policy regime of this country has gone through an extreme shift from a rigid to floating exchange rate with the adoption of inflation targeting policy. Therefore, it is interesting to examine the behaviour of monetary policy of Thailand focusing on two different periods: pre-crisis and post-crisis using the threshold estimations method as evidence found on the nonlinearity structure on both sub-periods. Our results indicating, the policy reaction function of Thailand is decided based on economic growth (LGDP) and inflation (LCPI) for pre- and post-crisis respectively. Overall, the policy rule is reacting strongly to inflation gap. While policy rule is also responsive to output gap but was limited only at the post-crisis period. On the other hand, we also detected the policy rule behaving adversely to exchange rate changes aftermath crisis. To conclude, the ultimate goal of Thai monetary policy is to achieve low inflation rate for price stability. Perhaps, output gap is not the major concern since the economy has achieved high stable growth. Although Thailand was implementing inflation targeting aftermath crisis, the results revealing the existence of 'fear of floating' behaviour when the policy rule reacting strongly towards appreciation of exchange rate by declining the policy rate.
\end{abstract}

(C) 2017 The Authors. Published by IASE. This is an open access article under the CC BY-NC-ND license (http://creativecommons.org/licenses/by-nc-nd/4.0/).

\section{Introduction}

Thailand has gone through drastic changes in economic structure and monetary policy regime after the financial turbulence (1997-98). The causes, changes and consequences experienced in Thailand and other Asian countries have attracted many researchers to examine the behaviour of the monetary policy in emerging economies, especially in the policy evaluation and decision making. In terms of monetary policy implementation, Thailand has transformed from monetary targeting to inflation targeting framework. While exchange rate regime has shifted from fixed/pegged to flexible/freely floating (Inoue et al., 2012).

Thus, there are doubts if such policy changes can lead to economic reformation and stable growth. Can the monetary policy framework effectively control the price stability? Does monetary policy interact with exchange rate changes incorporating to

\footnotetext{
* Corresponding Author.

Email Address: resshma06@yahoo.com (L. Manogaran) https://doi.org/10.21833/ijaas.2017.012.013

2313-626X/C 2017 The Authors. Published by IASE.

This is an open access article under the CC BY-NC-ND license

(http://creativecommons.org/licenses/by-nc-nd/4.0/)
}

external shocks? To answer such questions, it is crucial to examine the behavior of monetary policy in reacting to economic variables or policy targets between the two policy regimes. Since the understanding on the policy reaction or dynamic behaviour may provide more sophisticated information on the interaction between economic variables and monetary policy variables and the transmission of shocks. Therefore, in this study we apply the threshold estimation approach on estimating the monetary policy of Taylor-typed rule in order to examine the policy behaviour and observe the policy stance in Thailand. In particular, our main objective is to examine the changes of policy reaction function or behaviour between the pre- and post-crisis or under two different policy regimes after the financial crisis. In addition, we also seek to reveal if there is any asymmetric behaviour captured on the policy rule resulting from the influence of certain indicators/factors in Thailand.

The empirical estimations on the policy rule of Thailand is determined by two different indicators; economic growth (LGDP) for pre-crisis and inflation (LCPI) for post-crisis as the policy rule reacts differently following the movement of these two threshold variables. On the whole, the estimations 
for both sub-periods showed that the policy rule is reacting significantly to its own lag indicating slow and partial adjustment in the policy rate. The findings also proved that the policy rule is reacting strongly in response to inflation gap in pre- and post-crisis periods at all threshold values. Besides that, policy rule is also responding to output gap which is limited only at the post-crisis period. The results testified, the main focus of policy target is on inflation which confirms the execution of inflation targeting framework in Thailand aftermath crisis. Under this strategy, the main objective is to achieve low inflation rate towards price stability. Yet output gap is not the major concern of policymaker since Thai economy has achieved high stable growth.

Other than inflation and output gaps, observing the pre- and post-crisis period, the empirical findings suggested that the policy rule is not responsive to exchange rate changes in the pre-crisis period. This is probably because Thai economy was implementing a fixed exchange rate regime (baht was pegged to US dollar) at that point of time. Conversely, aftermath crisis the policy rule is reacting significantly to exchange rate changes, showing an inverse behaviour in majority of the threshold values. Nevertheless, Thailand has implemented a free-floating regime aftermath crisis; the results affirmed the existence of 'fear of floating' behaviour when the policy rule is reacting to the appreciation of exchange rate changes by declining the policy rate. From this, we can conclude that the Thai monetary policy rule is not only reacting to inflation and output gaps perhaps also towards exchange rate changes through adjustment in the policy rule, although officially declaring a free floating regime in the post-crisis period.

The rest of this paper is structured as follows; Section 2 is the literature review, the discussion on 'fear of floating' behaviour and related empirical findings. Section 3 reports the background study on the evolution of monetary policy in Thailand. Section 4 explains the data source and methodology of the study. Section 5 renders the results and discussions. Finally, the last section concludes the findings.

\section{Literature review}

The monetary policy in emerging economies always exhibit the 'fear of floating' behaviour (Calvo and Reinhart, 2002). These economies are reluctant to float their currencies as they are vulnerable to external shocks and exchange rate fluctuation, despite the fact to strictly float their currency by implementing inflation targeting strategy (Mohanty and Klau, 2004).

There are arguments that inflation targeting does not work well in emerging economies context, resulting from the intervention of policymakers to limit the exchange rate changes which lead to no more freely floating exchange rate regime. Theoretically, a well-performing inflation targeting regime, always accompanied by flexible/free-floating exchange rate (Taylor, 2001). This related to 'impossible trinity' concept where policymaker has the restriction to choose any two of the following three choices from monetary independence, perfect capital mobility and fixed exchange rate (Mukherjee, 2011). Thus, capital mobility and independence of monetary policy cannot co-exist with fixed exchange rate. While, the middle regime which is not fully flexible or fixed is not sustainable (Taylor, 2001).

Empirical studies also revealed evidences on the 'fear of floating' behaviour in emerging economies. Aizenman et al. (2011) examined sixteen emerging economies with and without inflation targeting and reported the inflation targeting countries are reacting to real exchange rate in the policy rate setting with the reason of 'fear of floating' behaviour. While Caporale et al. (2016) examined the policy rule of five inflation targeting emerging economies and reported the augmented Taylor rule with exchange rate is best describing the behaviour of the policy settings as most them are vulnerable to external shocks. Further, Galimberti and Moura (2013) conducted panel estimation for fifteen emerging economies which have adopted freefloating exchange rate regime accompanied inflation targeting. The analyses reported evidences that the policy settings are reactive to exchange rate changes. Taguchi (2011) studied the emerging Asian economies that moved towards floating regime. The investigation claimed independent monetary policy setting co-exist with accumulation of foreign reserves which implying the 'fear of floating' behaviour.

On the other hand, some studies do not reveal intervention on exchange rate by policymaker. Brenner and Sokoler (2010) conducted study in the case of Israel and found no 'fear of floating' behaviour in the policy rule setting and it is conducted in a free-floating regime. Further, Mukherjee (2011) in her studies identified that the inflation targeting central banks with monetary independence losses control on exchange rate changes and let exchange rate float freely when there is perfect/larger capital mobility which affirming a rule-like behaviour in the policy setting.

To be more specific, also reporting some studies based on the analyses of Thailand. As found in Lueangwilai (2012), policymaker of Thailand consider exchange rate movements in their policy setting by implementing flexible inflation targeting policy where exchange rate matters. On the other hand, Pornpattanapaisankul (2010) estimated the policy rule of Thailand that has implemented inflation targeting strategy and reported, the policy rule is reacting to inflation rate but not bothering the exchange rate, which revealing the absence of 'fear of floating' behaviour.

From the empirical analyses above, we may conclude; what a country say and really do may vary especially for emerging economies with inherent financially vulnerable and open in trade. In particular, for the case of Thailand, there are two contradicting results. Therefore, there is an urge to empirically estimate the policy reaction function 
setting of Thailand to ascertain its real behaviour before and after crisis at two different monetary policy settings.

\section{Background of study}

Over the ten years between 1987 and 1996, Thailand was pride in record of economic stability with relatively low inflation rates (approximately $4.7 \%$ ) and an uninterrupted economic growth (average annual GDP growth of 9.4\%) accompanied with relatively high policy rate (interest rate). Concurrently the stable fixed/pegged exchange rate regime of Thailand (Don, 2009; Jansen, 2001) has attracted large foreign direct investment (FDI) which increased the exports and obtained trade surplus with large capital inflows through its low-waged and low-skilled labour force (Quan, 1998). As the result of open foreign investment and market-friendly ideology, Thailand was once praised by the World Bank (Julian, 2000). Following, continuous rapid economic growth with stable exchange rate (US dollar-baht pegged) encouraged Thailand to be more liberalized in its financial sector decision making. Thus most of the domestic companies borrowed extensively from foreign bankers/countries. The loans were in U.S dollars since the interest rates remarkably low than the Thai currency (baht) with speculation and expectation of profit from the lower interest rates (Quan, 1998).

Disastrously when the US dollar appreciated, Thailand became less competitive in the world market as result the net exports and revenue declined. Continuously the outstanding external debt rose from 28.8 billion US dollars (33.8\% of GDP) in 1990 to 94.3 billion US dollars (50.9\% of GDP) at the end of 1996. This slow-down the economy of Thailand with lower growth rate and also increased the current account deficit which co-exist with the lost in stock exchange market (Lauridsen, 1998). This dilemma vigorously forced most investors to sell the Thai baht which later depreciated from 25 baht/US dollar to 55 baht/US dollar by early January 1998. Although the central bank of Thailand (BOT) used larger amount of their reserves to defend the baht. Yet, on 2nd July 1997 the world market forced the central bank to float the baht.

To overcome the turbulence, Thailand was sourced by the IMF, World Bank and central banks of Japan and Asia with a programme which was announced on $20^{\text {th }}$ of August 1997. In this IMF borrowed \$US4 billion (505\% of the Thai quota), World Bank \$US1.5 billion, Japan \$US4 billion and the Asian Development Bank \$US1.2 billion (Ito, 2007). Followed by the adoption of floating exchange rate system and the IMF program, a monetary targeting regime was adopted (July 1997 - April 2000). At this time, the policy objective was to recover the confidence from the failure of fixed exchange rate regime with an effort to regain the macroeconomic stability. Under this regime, BOT set the daily and quarterly monetary base targets and put upward pressure on interest rates if base money was running ahead of the medium-term targets, and put downward pressure on interest rates if base money was below such targets. At a point of time, the relationship between the money supply and output growth became less stable and the monetary targeting was assumed to be inappropriate (Don, 2009).

Hence withdrawal from the IMF programme became another reason for the authorities to identify a well - suited monetary policy (Inoue et al., 2012). Thus, on April 2000 the BOT appointed the Monetary Policy Board (MPB) as the policy-making body and officially moved towards a flexible/floating exchange rate regime while adopting inflation targeting as the monetary policy strategy (Don, 2009; Ghosh and Rajan, 2008) where price stability or low inflation rate is the foremost objective to attain sustainable economic growth (Don, 2009).

\section{Data and methodology}

In examining the behaviour of policy reaction function of Thailand before and aftermath the crisis, we employed quarterly time series data which covers two different phases: pre-crisis (1980Q1 1996Q4) and post-crisis (1999Q1 - 2015Q4). The relevant data was extracted from Datastream. The main variables are namely, central bank interest rate $(I N T)$ in percentage, consumer price index $(C P I)$ in index form, gross domestic product (GDP) in US dollar and real exchange rate (REER) per US dollar. All the variables involved are converted to natural logarithm, except the interest rates which are in percentages form with the purpose to streamline the data. Further, CPI inflation (CINF) is obtained using $\log C P I(L C P I)$ deviates from its lagged 4 (proxy for annual rate). On the other hand, output gap (GAP) is constructed as log gross domestic product ( $L G D P$ ) deviates from its trend obtained via the HodrickPrescott filter. Then, the exchange rate changes (DLREER) is the first differenced of log REER.

In this paper, we seek to estimate the policy rule as in (Mehrotra and Sanchez-Fung, 2009) (Eqs. 1, 2, and3):

$i_{t}=a_{0}+a_{1}\left(\pi_{t}-\pi^{*}\right)+a_{2}\left(y_{t}-\tilde{y}\right)+a_{3} \Delta e_{t}+a_{4} i_{t-1}+\varepsilon_{t}$
$i_{t}^{*}=c_{0}+\alpha\left(\pi_{t}-\pi^{*}\right)+\beta\left(y_{t}-\tilde{y}\right)+\delta \Delta e_{t}$
$i_{t}=(1-\rho) i_{r}^{*}+\rho i_{t-1}+\varepsilon_{t}$

where $\rho$ is the smoothing coefficient takes the value between 0 and 1 ;

$a_{0}=(1-\rho) c_{0} \cdot a_{1}=(1-\rho) \alpha, a_{2}=(1-\rho) \beta, a_{3}=(1-$ $\rho) \delta$

and $a_{4}=\rho$; $i_{t}^{*}$ is the central bank nominal rate; $i_{t}$ is the central bank actual or real rate; $\left(\pi_{t}-\pi^{*}\right)$ is the deviation between inflation and targeted rate; $\left(y_{t}-\tilde{y}\right)$ is the output gap indicating the actual growth deviates from its potential rate; $\Delta e_{t}$ is the changes in nominal exchange rate. This policy rule in 
Eq. 2 is the Taylor rule augmented with smoothing term, $i_{t-1}^{*}$ and exchange rate changes term.

In capturing the possibly asymmetric response in policy rule, the threshold regression is applied so that our policy rule now takes the following form (Eqs. 1 and 2):

$i_{t}=I\left[x_{t} \geq x_{1}^{*}\right]\left[a_{0}+a_{1}\left(\pi_{t}-\pi^{*}\right)+a_{2}\left(y_{t}-\tilde{y}\right)+a_{3} \Delta e_{t}+\right.$

$\left.a_{4} i_{t-1}\right]+I\left[x_{t}<x_{1}^{*}\right]\left[b_{0}+b_{1}\left(\pi_{t}-\pi^{*}\right)+b_{2}\left(y_{t}-\tilde{y}\right)+\right.$

$\left.b_{3} \Delta e_{t}+b_{4} i_{t-1}\right]+\varepsilon_{t}$

$i_{t}=I\left[x_{t} \geq x_{1}^{*}\right]\left[a_{0}+a_{1}\left(\pi_{t}-\pi^{*}\right)+a_{2}\left(y_{t}-\tilde{y}\right)+a_{3} \Delta e_{t}+\right.$

$\left.a_{4} i_{t-1}\right]+I\left[x_{2}^{*}<x_{t}<x_{1}^{*}\right]\left[b_{0}+b_{1}\left(\pi_{t}-\pi^{*}\right)+b_{2}\left(y_{t}-\tilde{y}\right)+\right.$

$\left.b_{3} \Delta e_{t}+b_{4} i_{t-1}\right]+I\left[x_{t} \geq x_{2}^{*}\right]\left[c_{0}+c_{1}\left(\pi_{t}-\pi^{*}\right)+\right.$

$\left.c_{2}\left(y_{t}-\tilde{y}\right)+c_{3} \Delta e_{t}+c_{4} i_{t-1}\right]+\varepsilon_{t}$

where $i$ indicating the threshold effect. $x_{t}=$ $L G D P_{t}, L C P I_{t}$ denotes the threshold variables while $x_{1}^{*}$ and $x_{2}^{*}$ are the threshold values by limiting the number of threshold to at most 2. Eq. 4 is the threshold equation with one threshold value while Eq. 5 has two threshold values. The two threshold variables $L G D P_{t}$ and $L C P I_{t}$ are selected for pre-crisis and post-crisis periods respectively based on the lowest Akaike Information Criteria (AIC) as they are important indicators to the policy targets of inflation deviation $\left(\pi_{t}-\pi^{*}\right)$, output gap $\left(y_{t}-\tilde{y}\right)$ and exchange rate changes $\Delta e_{t}$. The threshold regression is based on Bai-Perron tests of $\mathrm{L}+1$ vs. $\mathrm{L}$ sequentially determined thresholds where the test statistically employs the White heteroscedasticity-consistent covariance and also allowing heterogeneous error distributions across thresholds. For details, see Bai and Perron (1998).

\section{Results and discussions}

Prior to the estimation, unit-root tests are performed on checking the stationarity of all variables based on constant and trend specification at two sub-periods. All the four tests, i.e. Augmented Dickey-Fuller (ADF), Kwiatkowski-PhillipsSchmidt-Shin (KPSS), Phillips-Perron (PP) and Breakpoint (BP) showed very similar results (Table 1).

Table 1: Unit root tests statistics

\begin{tabular}{|c|c|c|c|c|}
\hline \multicolumn{5}{|c|}{ Pre-crisis period } \\
\hline Variable & ADF & KPSS & $\mathrm{PP}$ & $\mathrm{BP}$ \\
\hline INT & $-2.8899 *$ & $0.5938 * *$ & $-2.8394^{*}$ & $-4.3283^{*}$ \\
\hline CINF & $-2.3432^{* *}$ & 0.1498 & $-3.9514^{* * *}$ & $-4.5092^{* *}$ \\
\hline$G A P$ & -0.2371 & 0.3115 & -0.7247 & -3.1783 \\
\hline DLREER & $-6.8822^{* * *}$ & 0.2799 & $-6.8394 * * *$ & $-7.3635^{* * *}$ \\
\hline \multicolumn{5}{|c|}{ Post - crisis period } \\
\hline Variable & ADF & KPSS & $\mathrm{PP}$ & $\mathrm{BP}$ \\
\hline$I N T$ & $-5.4776^{* * *}$ & 0.0983 & $-6.1040 * * *$ & $-6.0446^{* * *}$ \\
\hline CINF & $-5.1247^{* * *}$ & 0.1908 & $-3.3333^{* *}$ & $-5.7014^{* * *}$ \\
\hline GAP & $-3.7806^{* * *}$ & 0.1567 & $-3.6570 * * *$ & $-4.8029 * *$ \\
\hline DLREER & $-6.7398^{* * *}$ & 0.1465 & $-6.6299 * * *$ & $-7.0919^{* * *}$ \\
\hline
\end{tabular}

ADF, PP and BP tests reject the null hypothesis of unit-root while KPSS fail to reject the null hypothesis of stationary, indicating, all variables are stationary at levels or $\mathrm{I}(0)$ which permitting to regress the variables in levels. In addition, BDS independence test is also performed to examine the nonlinearity behaviour of each variable (Brock et al., 1996). As observed from the results in Table 2, BDS test is able to reject the assumption of independence in most cases, this indicating the nonlinearity structure of all variables in both sub-periods. Thus, the application of threshold regression is relevant for our studies.

Table 2: Nonlinearity test - BDS test statistics

\begin{tabular}{ccccc}
\hline \multicolumn{5}{c}{ Pre - crisis period } \\
\hline Dimension & $I N T$ & $C I N F$ & $G A P$ & $D L R E E R$ \\
\hline 2 & $0.1691^{* * *}$ & $0.1495^{* * *}$ & $0.1194^{* * *}$ & $0.0356^{* * *}$ \\
3 & $0.2872^{* * *}$ & $0.2418^{* * *}$ & $0.1831^{* * *}$ & $0.0560^{* * *}$ \\
4 & $0.3587^{* * *}$ & $0.2890^{* * *}$ & $0.2130^{* * *}$ & $0.0734^{* * *}$ \\
5 & $0.3994^{* * *}$ & $0.3066^{* * *}$ & $0.2251^{* * *}$ & $0.0797^{* * *}$ \\
6 & $0.4230^{* * *}$ & $0.3145^{* * *}$ & $0.2257^{* * *}$ & $0.0825^{* * *}$ \\
\multicolumn{5}{c}{ Post - crisis period } \\
\hline Dimension & $I N T$ & $C I N F$ & $G A P$ & $D L R E E R$ \\
\hline 2 & $0.1441^{* * *}$ & $0.0940^{* * *}$ & $0.0495^{* * *}$ & 0.0082 \\
3 & $0.2355^{* * *}$ & $0.1456^{* * *}$ & $0.0588^{* * *}$ & 0.0064 \\
4 & $0.2881^{* * *}$ & $0.1772^{* * *}$ & $0.0694^{* * *}$ & $0.0293^{*}$ \\
5 & $0.3153^{* * *}$ & $0.1909^{* * *}$ & $0.0732^{* * *}$ & 0.0256 \\
6 & $0.3234^{* * *}$ & $0.2051^{* * *}$ & $0.0759^{* * *}$ & 0.0254 \\
\hline Note: ${ }^{* * *}$ indicates significance at $1 \%$ and & significance at $10 \%$
\end{tabular}

Table 3 summarized the results from threshold estimations. Testing with several threshold variables up to at most two threshold breaks, our results showed that the policy rule of Thailand is determined by economic growth (LGDP) and inflation (LCPI) in the pre- and post-crisis periods respectively. In brief, the policy rule is reacting differently to inflation gap, output gap and exchange rate changes under these two different threshold variables. In particular, the policy rule is responding strongly to inflation gap across two sub-periods. In this case, the policymaker tends to implement contractionary policy by raising the policy rate to accommodate higher inflation gap except when inflation threshold is considerable low $(L C P I<4.3164)$. Such strong reaction on inflation gap proved that low inflation is the main policy target in Thailand. On the other hand, the reaction to output gap is limited/not significant in both sub-periods except when inflation threshold is considerable low $(L C P I<4.3164)$ in the post-crisis.

This implies that output gap is not the main concern since Thai economy has achieved high stable growth. Besides that, the policy rule also reacting to its own lagged, indicating slow adjustment in the policy rate across both pre- and post-crisis periods.

Comparing the policy behaviour across two subperiods, we observed very different policy reaction to exchange rate changes under these two different policy regimes. In the pre-crisis period, there is no significant reaction of policy rate to exchange rate changes. This is because Thai Baht was pegged to US dollar and no adjustment needed to influence the exchange rate movement. However, the policy rule reacting strongly to exchange rate changes in the post-crisis period after Thailand switched to floating exchange rate accompanied with inflation targeting regime. The policy rate was lower in response to exchange rate appreciation. Although Thailand officially announced to be free floater in the postcrisis period, the policy rule is still responding to 
exchange rate changes or intervention of policymaker to accommodate the exchange rate movements. Remarkably, these results implying the 'fear of floating' behaviour in Thailand.

Table 3: Threshold regression estimations

\begin{tabular}{cccc}
\hline \multicolumn{4}{c}{ Pre-crisis coefficients (Threshold: LGDP) } \\
\hline Variable & LGDP<9.4227 & $9.4227 \leq$ LGDP<9.8200 & LGDP $\geq 9.8200$ \\
CINF & $75.6830^{* * *}$ & $107.0890^{*}$ & $126.3745^{* * *}$ \\
GAP & -2.9668 & 2.9441 & -2.0214 \\
DLREER & 5.0990 & -10.2087 & 8.0357 \\
INT(-1) & $0.2771^{*}$ & $0.4246^{* *}$ & $0.3111^{* *}$ \\
$\mathrm{C}$ & $5.4827^{* * *}$ & 0.9250 & -0.3736 \\
$\mathrm{R}^{2}$ & 0.9284 & 0.9284 & 0.9284 \\
Obs & 24 & 9 & 31 \\
\hline \multicolumn{4}{c}{ Post-crisis coefficients (Threshold: LCPI) } \\
\hline Variable & LCPI<4.3164 & $4.3164 \leq$ LCPI<4.4916 \\
CINF & $-23.5905^{* * *}$ & $15.7975^{* * *}$ & LCPI $\geq 4.4916$ \\
GAP & $41.2018^{* * *}$ & -2.2975 & $9.3244^{* * *}$ \\
DLREER & $-25.4770^{* * *}$ & 2.4464 & 1.5390 \\
INT(-1) & $0.7076^{* * *}$ & $0.9332^{* * *}$ & $-3.8605^{* * *}$ \\
$\mathrm{C}$ & $0.1343^{* * *}$ & -0.1648 & $0.7056^{* * *}$ \\
$\mathrm{R}^{2}$ & 0.9609 & 0.9609 & $0.4354^{* * *}$ \\
Obs & 6 & 27 & 0.9609 \\
\hline Note: ${ }^{*}$ indicates significance at $10 \%{ }^{* *}$ significance at $5 \%$ and ${ }^{* * *}$ significance at $1 \%$
\end{tabular}

Finally, we also performed two diagnostic tests to further assess residuals of estimation which presented in Table 4. The testing on the residuals of estimates for autocorrelation (LM test) (Breusch, 1978; Godfrey, 1978) and heteroscedasticity (ARCH test)(Engle, 1982) fail to reject the null hypothesis of autocorrelation and heteroscedasticity which confirming our results are reliable.

Table 4: Diagnostic tests

\begin{tabular}{ccc}
\hline Variables & Pre-crisis & Post-crisis \\
\hline LM Test (F-stat) & 0.9096 & 1.7977 \\
P-value & $(0.4096)$ & $(0.1760)$ \\
ARCH Test (F-stat) & 2.0006 & 0.1868 \\
P-value & $(0.1443)$ & $(0.8301)$ \\
\hline
\end{tabular}

\section{Conclusion}

In this paper, empirical analyses are performed on examining the behaviour of monetary policy of Thailand. Our main objective is to compare the policy behaviour or reaction function between preand post-crisis as Thailand has experienced drastic changes from fixed exchange rate to flexible one coexist with inflation targeting regime after financial crisis of 1997-1998. In particular, we seek to capture the asymmetric reaction of policy rule to the policy targets: inflation gap and output gap. In addition, we also seek to examine if the policy rule reacts to exchange rate changes under two different exchange rate regimes. Our results reveal that the policy rule of Thailand is determined by economic growth (LGDP) for pre-crisis and inflation (LCPI) for postcrisis as it reacts differently following the movement of these two threshold variables.

Overall, the threshold estimations prove that the policy rule is reacting strongly to inflation gap. On the other hand, the policy rule is less responsive to output gap which is limited only at the post-crisis period. The policy rule also exhibits the partial or gradual adjustment across the two sub-periods. Comparing the pre- and post-crisis periods, we observe no response from the policy rule to exchange rate changes in the pre-crisis probably because exchange rate was pegged to US dollar. However, policy rule reacts strongly to exchange rate changes in the post-crisis which is under the freefloating regime. Although Thailand adopted inflation targeting aftermath the financial crisis, the results imply the existence of 'fear of floating' behaviour when the monetary policy rule is reacting to the appreciation of exchange rate changes by declining the policy rate. This concludes that the monetary policy rule of Thailand not only responding to inflation gap, output gap perhaps also to exchange rate changes through adjustment in the policy reaction function aftermath the financial crisis.

\section{Acknowledgment}

This work is funded by FRGS grant, 203/PMATHS/6711431.

\section{References}

Aizenman J, Hutchison M, and Noy I (2011). Inflation targeting and real exchange rates in emerging markets. World Development, 39(5): 712-724.

Bai J and Perron P (1998). Estimating and testing linear models with multiple structural changes. Econometrica, 66(1): 47-78.

Brenner M and Sokoler M (2010). Inflation targeting and exchange rate regimes: Evidence from the financial markets. Review of Finance, 14(2): 295-311.

Breusch TS (1978). Testing for autocorrelation in dynamic linear models. Australian Economic Paper, 17(31): 334-355.

Brock WA, Dechert WD, Scheinkman JA, and LeBaron B (1996). A test for independence based on correlation dimension. Econometric Reviews, 15(3): 197-235.

Calvo GA and Reinhart CM (2002). Fear of floating. The Quarterly Journal of Economics, 117(2): 379-408.

Caporale GM, Çatık N, Helmi MH, Ali FM, and Akdeniz C (2016). Monetary policy rules in emerging countries: Is there an augmented nonlinear taylor rule?. Center for Economic Studies and ifo Institute (CES ifo), Working Paper Series No. 5965. Available at SSRN: https://ssrn.com/abstract=2814467

Don N (2009). Thailand 's monetary policy since the 1997 crisis. Kobe University Economic Review, 55: 75-88. 
Engle RF (1982). Autoregressive conditional heteroscedasticity with estimates of the variance of United Kingdom inflation. Econometrica, 50(4): 987-1007.

Galimberti JK and Moura ML (2013). Taylor rules and exchange rate predictability in emerging economies. Journal of International Money and Finance, 32: 1008-1031.

Ghosh A and Rajan RS (2008). Exchange rate pass-through in Korea and Thailand: trends and determinants. Japan and the World Economy, 21(1): 55-70.

Godfrey LG (1978). Testing against general autoregressive and moving average error models when the regressors include lagged dependent variables. Econometrica, 46(6): 1293-1301.

Inoue T, Toyoshima Y, and Hamori S (2012). Inflation targeting in Korea, Indonesia, Thailand, and the Philippines: The impact on business cycle synchronization between each country and the world. IDE Discussion Paper No. 328. Institute of Developing Economies, JETRO, Chiba, Japan. Available online at: http://hdl.handle.net/2344/1117

Ito $\mathrm{T}$ (2007). Asian currency crisis and the international monetary fund, 10 years later: Overview. Asian Economic Policy Review, 2(1): 16-49.

Jansen K (2001). Thailand, financial crisis and monetary policy. Journal of the Asia Pacific Economy, 6(1): 124-152.

Julian CC (2000). The impact of the Asian economic crisis in Thailand. Managerial Finance, 26(4): 39-48.

Lauridsen LS (1998). The financial crisis in Thailand: Causes, conduct and consequences?. World Development, 26(8): 1575-1591.
Lueangwilai K (2012). Monetary policy rules and exchange rate uncertainty: A structural investigation in Thailand. Procedia Economics and Finance, 2: 325-334.

Mehrotra A and Sanchez-Fung JR (2009). Assessing McCallum and Taylor rules in a cross-section of emerging market economies. BOFIT Discussion Papers, 23: 1-22.

Mohanty MS and Klau M (2004). Monetary policy rules in emerging market economies: Issues and evidence. Bank for International Settlements, Working Paper No. 149. Available at SSRN: https://ssrn.com/abstract $=901388$ or http://dx.doi.org/10.2139/ssrn.901388

Mukherjee S (2011). Does the level of capital openness explain "fear of floating" amongst the inflation targeting countries?. Munich Personal RePEc Archive (MPRA), MPRA Paper No. 30289. Available online at: https://mpra.ub.unimuenchen.de/id/eprint/30289

Pornpattanapaisankul K (2010). Monetary policy rule under an inflation targeting framework: Evidence from Thailand. M.Sc. Thesis, Thammasat University, Bangkok, Thailand.

Quan BL (1998). Currency crisis in Thailand: The leading indicators. The Park Place Economist, 8: 66-71.

Taguchi H (2011). Monetary autonomy in emerging market economies: The role of foreign reserves. PRI Discussion Paper Series, 12(4): 371-388.

Taylor JB (2001). The role of the exchange rate in monetary-policy rules. The American Economic Review, 91(2): 263-267. 